\title{
CERTIFICAÇÕES SUSTENTÁVEIS: A INFLUÊNCIA DO INVESTIMENTO ESTRANGEIRO DIRETO EM EMPRESAS DA INDÚSTRIA SUCROENERGÉTICA NO BRASIL
}

\author{
Sustainable Certifications: The Influence of Foreign Direct Investment \\ in Sugarcane Industry Firms in Brazil
}

\begin{abstract}
RESUMO
O objetivo desta pesquisa é analisar a influência do investimento estrangeiro direto e da capacidade produtiva na adoção de certificações sustentáveis no setor sucroenergético brasileiro. O levantamento de dados foi feito a partir de uma amostra composta por 100 usinas que representam 58\% das empresas em operação no estado de São Paulo. Os dados foram analisados com o modelo multivariado de regressão logística binomial. Os resultados não suportam a hipótese de que o investimento estrangeiro direto tenha um relacionamento positivo com as certificações sustentáveis. Já a hipótese de que a capacidade produtiva está positivamente relacionada com a adoção de certificação sustentável foi estatisticamente significante. Os resultados sugerem que o impacto positivo dos investimentos diretos estrangeiros na sustentabilidade do país local depende da ocorrência de fortes instituições governamentais e da qualidade da fiscalização da conduta das empresas, além da capacidade de absorção e aprendizagem que as organizações devem possuir diante do fluxo de investimento estrangeiro. Já do relacionamento da capacidade produtiva - moagem - com a busca por certificações, pode ser depreendido que as usinas maiores exportam seus produtos para mercados especializados e mais exigentes, a certificação é um pré-requisito para a compra e venda. Dessa forma, esta pesquisa contribui para a literatura existente por avançar em temáticas cujo relacionamento é pouco estudado, principalmente nesse setor.
\end{abstract}

Nayele Macini

Faculdade de Economia, Administração e Contabilidade de Ribeirão Preto

nmacini@yahoo.com.br

Marlon Fernandes Rodrigues Alves

Faculdade de Economia, Administração e Contabilidade de Ribeirão Preto

mfralves@fearp.usp.br

Larissa Marchiori Pacheco

Fundação Getúlio Vargas

lari.marchiori@gmail.com

Adriana Cristina Ferreira Caldana

Faculdade de Economia, Administração e Contabilidade de Ribeirão Preto

caldana@fearp.usp.br

Patrícia Lima Denipotti Aveiro

Ouro Fino Saúde Animal LTDA.

patriciadenipotti@gmail.com

Recebido em: 01/03/2016. Aprovado em: 24/07/2017

Avaliado pelo sistema double blind review

Avaliador científico: Daniel Carvalho de Rezende

DOI: $10.21714 / 2238-68902017 v 19 n 2 p 137$

\begin{abstract}
The objective of this research is to analyze the influence of direct foreign investment and of the productive capacity in the adoption of sustainable certifications in Brazilian sugarcane sector. The data survey was done from a sample comprised by 100 mills, which represent $58 \%$ of the companies operating in the state of São Paulo, Brazil. The data were analyzed with the multivariate binomial logistic regression model. The results do not support the hypothesis that direct foreign investment has positive relation with sustainable certifications. The hypothesis that productive capacity is positively related to the adoption of sustainable certification was statistically significant. The results suggest that the positive impact of direct foreign investment on the sustainability of the local country depends on the occurrence of strong governmental institutions and of the quality of corporate conduct supervision, as well as the absorption and learning capacity that organizations must present in view of the flow of foreign investment. Regarding the relationship of productive capacity - milling - with the search for certifications, it can be seen that the larger mills export their products to specialized and more demanding markets, with certification being a prerequisite for buying and selling. Thus, this study contributes to the existing literature by advancing in themes of whicg relation is understudied, especially in this sector.
\end{abstract}

Palavras-chave: Bonsucro, Sustentabilidade, Moagem, Logit.

Keywords: Bonsucro, Sustainability, Milling, Logit. 


\section{INTRODUÇÃO}

O setor sucroenergético no Brasil, em termos de significado econômico, social e ambiental, apresenta uma estrutura produtiva de 430 unidades, 70 mil produtores de cana-de-açúcar, e 1,2 milhões de empregos diretos gerados, além de um Produto Interno Bruto de US\$ 48 milhões e as exportações em US\$ 15 bilhões (UNIÃO DA INDÚSTRIA DE CANA-DE-AÇÚCAR, 2015). Com o rápido crescimento do país e a crescente demanda mundial por energias renováveis, as organizações passaram a ter exigências de adaptações e inovações ao gerirem tanto seus produtos, como suas produções, a fim de auferirem vantagens competitivas (GUIDO; LIMA, 2012; RUVIARO et al., 2012). Assim, os impactos sociais e ambientais advindos dessas mudanças, junto à crescente consciência pública envolvendo a sustentabilidade, passaram a ser levados em consideração na gestão do setor.

Apesar do potencial cenário brasileiro de exportações de biocombustíveis, algumas manifestações surgiram, principalmente advindas do mercado europeu, referentes aos impactos socioambientais produzidos pelo setor. Com as pressões, a União Europeia agregou na Diretiva 2009/28/CE a exigência de certificações, tanto nos biocombustíveis produzidos internamente, quanto para os importados (SAMPAIO; BORSCHIVER; MORGADO, 2012). As certificações ganham expressão nesse contexto, na medida em que oferecem uma prova concreta de que os requisitos de sustentabilidade têm sido atendidos, bem como proporcionam um direcionador para a operacionalização de estratégias de sustentabilidade nas empresas (OLIVEIRA et al., 2012).

Especificamente para o setor sucroenergético, a iniciativa Bonsucro foi desenvolvida para a avaliação da produção de etanol e da sustentabilidade na produção do açúcar (SAMPAIO; BORSCHIVER; MORGADO, 2012). Seu objetivo, a priori, era promover a produção sustentável da cana, por meio do estabelecimento das melhores práticas de gestão, visando a diminuir os impactos da produção e transformação do açúcar, mas posteriormente, desenvolveu um sistema capaz de assegurar a conformidade com os critérios de sustentabilidade implementados em 2011 (MOURA; CHADDAD, 2012).

Alcançar os mercados mais rigorosos passou a exigir a comprovação da sustentabilidade na produção do etanol e do açúcar. Ademais desse cenário, o tamanho do mercado doméstico brasileiro e a abertura comercial brasileira, aumentaram a atratividade para os investimentos estrangeiro direto (IED), com diversos grupos internacionais investindo intensamente no setor sucroenergético, com a aquisição de usinas, como os casos do Grupo Tereos e Louis Dreyfus Commodities (CASTRO; FERNANDES; CAMPOS, 2013).

Castro, Fernandes e Campos (2013) alegam que na economia globalizada, esse tipo de investimento (o IED) vem apresentando um importante papel, já que pode influenciar positivamente o crescimento econômico, o aumento de empregos, a melhoria da qualificação da mão de obra, fomentando, também, a capacidade tecnológica e produtiva do país. Tratando especificamente do setor sucroenergético, Oliveira et al. (2012) afirmam que os grupos estrangeiros são capazes de fomentar o desenvolvimento do comércio internacional de etanol, por garantirem o fornecimento continuado e por sua estrutura de exportação, que garantem a competitividade. Mas quando se consideram as métricas sociais e ambientais, há poucos estudos que explorem os efeitos dos investimentos estrangeiros (WANG et al., 2013).

Assim, a pergunta de pesquisa que motivou a condução desse estudo foi: qual a influência do capital estrangeiro na adoção de certificações sustentáveis no setor sucroenergético? E posto isso, a questão secundária a ser explorada foi a importância relativa da capacidade produtiva na adoção dessas certificações.

Logo, as hipóteses que pautam essa pesquisa são de que (1) a capacidade produtiva esteja positivamente relacionada com práticas de gestão sustentáveis, diante dos custos de implementação (SHIKIDA, 2013) e que (2) o investimento estrangeiro também esteja positivamente relacionado à adoção dessas práticas, atuando como indutor (KLINE, 2012).

Portanto, esta pesquisa se destaca por responder à carência de estudos que relacionem o investimento estrangeiro direto, a capacidade produtiva e a adoção de certificações sustentáveis, notadamente em um setor nos quais essas temáticas são pouco estudadas, o sucroenergético, mas que por outro lado, sofre com fortes pressões socioambientais pelos seus stakeholders. Além disso, contribui para a literatura existente sobre investimento estrangeiro direto em países emergentes, onde se carecem estudos envolvendo a sustentabilidade.

O estudo está dividido de forma que a seção 2 apresenta uma revisão sobre as fundamentações das hipóteses desta pesquisa. A terceira seção traz a metodologia, enquanto os resultados e discussão são abordados nas seções 4 e 5 , respectivamente. Na última seção (6), são apresentadas as considerações finais. 


\section{REFERENCIAL TEÓRICO}

\subsection{Sustentabilidade e as Certificações no Setor Sucroenergético}

O termo "desenvolvimento sustentável" se tornou notório por meio do documento "Our Common Future" - também conhecido como Relatório Brundtland - elaborado pela Comissão Mundial sobre Meio Ambiente e Desenvolvimento em 1987, e é concebido como "o desenvolvimento que satisfaz as necessidades presentes sem comprometer a habilidade das futuras gerações de suprir suas próprias necessidades" (UNITED NATIONS, 1987, p. 42).

Desde então, a questão da sustentabilidade ganhou centralidade nas discussões políticas e passou a ser direcionada às empresas, que são parte fundamental na promoção do desenvolvimento econômico de uma nação. Em se tratando das questões ambientais, as empresas enfrentam o desafio de contribuir com a diminuição do impacto ambiental, analisando o ciclo de vida do produto com vistas à redução do desperdício de recursos e da poluição (SMERENICK; ANDERSEN, 2011).

A Responsabilidade Social Corporativa (RSC) foi a primeira resposta prática das empresas para cumprir com tais premissas (BOLIS; BRUNORO; SZNELWAR, 2014). Com o passar do tempo, as questões ambientais e sociais passaram a ser inseridas nas responsabilidades das empresas e a pressão exercida pela sociedade e pelos governos para o seu cumprimento se intensificou. Atualmente, a abordagem mais conhecida para a sustentabilidade nas organizações é pautada entre os aspectos ambientais, econômicos e sociais de seus negócios - popularmente conhecida como Tripple Bottom Line (TBL), desenvolvida por Elkington, em 1997.

A sofisticação com que se aborda esse tema nas organizações passou da mitigação de externalidades para a integração da sustentabilidade nos modelos de negócio. Todavia, a pressão da sociedade para incorporação de melhores práticas sociais e ambientais não é uniforme: no Brasil, a comparação entre os indicadores do setor sucroenergético e o setor agrícola, em geral, apresenta diferenças com o setor sucroenergético melhor que o agrícola (MORAES; OLIVEIRA; DIAS-CHAVEZ, 2015).

Ainda, por mais que a cana-de-açúcar seja uma fonte renovável de energia, os impactos negativos do seu cultivo, extração e processamento não deixam de ser o maior foco das pesquisas (OLIVEIRA; PEREIRA; GASPAR, 2014).

A resposta que algumas empresas do setor encontraram para evidenciarem aos seus stakeholders que suas atividades cumprem além do mínimo exigido legalmente é a adoção de um sistema de gestão balizado por certificações socioambientais conferidas à empresa e seus produtos. De acordo com Hatanaka (2010), um sistema de certificação tem como objetivo enquadrar em normas préestabelecidas os produtos, serviços, sistemas e pessoas de uma organização. Nesse sentido, Oliveira, Pereira e Gaspar (2014) esclarecem que estas visam a garantir que os produtos e processos realizados pela empresa certificada estejam vinculados à questão da sustentabilidade dentro de suas três dimensões. Isso tende a permitir o acesso das empresas brasileiras do setor a diferentes mercados internacionais em função de seguirem as normas por eles estabelecidas (WILKINSON; HERRERA, 2010).

Existem diferentes certificações e padronizações no setor sucroenergético às quais as empresas podem aderir, as principais são: 2BSvs (Biomass Biofuels voluntary scheme); Greenergy (Greenergy Brazilian Bioethanol Verification Programme); BSI (Better Sugarcane InitiativeBonsucro); ISCC (International Sustainability and Carbon Certification); RSB (Roundtable on Sustainable Biofuels); RSBA (Abengoa RED Bioenergy Sustainability Assurance); RTRS (Round Table on Responsible Soy) (UNIÃO DA INDÚSTRIA DE CANA-DE-AÇÚCAR, 2013).

Nesta pesquisa, optou-se pela análise da certificação Better Sugarcane Initiative (BSI - Bonsucro), dado seu enfoque específico em práticas de sustentabilidade nas empresas do setor sucroenergético. A certificação Bonsucro é um padrão métrico global adotado voluntariamente e que tem como objetivo aprimorar os aspectos sociais, ambientais e econômicos envolvidos na produção de cana-de-açúcar e seus derivados, como açúcar e etanol (BONSUCRO, 2015; CERTIFICAÇÃO..., 2013).

Esta é fruto de uma iniciativa realizada em 2005 e formalizada em 2009 como uma organização sem fins lucrativos no Reino Unido composta por partes interessadas do setor sucroenergético (BONSUCRO, 2015; CERTIFICAÇÃO..., 2013). Desde então, está atuante como um fórum internacional reunindo produtores, organizações não governamentais (ONGs), empresas e investidores com o principal objetivo de assegurar um futuro sustentável para a produção de cana-de-açúcar por meio de iniciativas social e ambientalmente responsáveis (CRESCE..., 2013; MOURA; CHADDAD, 2012).

O processo de padronização Bonsucro se dedica a demonstrar por meio de impactos mensuráveis de que forma a empresa apoia os direitos humanos e está preocupada em implementar práticas ambientalmente corretas. Os padrões são baseados em cinco princípios e critérios básicos que foram desenvolvidos pelos 
membros e especialistas do setor: (1) obedecer a lei, (2) respeitar os direitos humanos e as leis trabalhistas, (3) gerenciar entrada, produção e processamento de eficiência para aumentar a sustentabilidade; (4) gerir ativamente a biodiversidade e serviços ecossistêmicos, e (5) comprometem-se à contínua melhoria em áreas-chave do negócio (CERTIFICAÇÃO..., 2013).

Além disso, intencionando se tornar um padrão internacional, a certificação Bonsucro buscou contemplar, também, as exigências métricas da Diretiva Europeia para Energias Renováveis (Diretiva 2009/28/EC) (BONSUCRO, 2015; CRECE..., 2013). Como resultado desse esforço, a Comissão Europeia passou a reconhecer a certificação como voltada a alcançar a produção sustentável de cana de açúcar e seus respectivos produtos, nas questões sociais, ambientais e econômicas. Logo, as empresas tornam-se aptas a comercializarem seus produtos para países integrantes da União Europeia (UE), com atestado de condições sustentáveis de fabricação (CRECE..., 2013; SAMPAIO; BORSCHIVER; MORGADO, 2012).

Outro reconhecimento foi dado pela Organização para a Cooperação e Desenvolvimento Econômico (OCDE), ao verificar que a Bonsucro possibilita que parceiros do setor sucroenergético se envolvam em um diálogo construtivo para desenvolver e incentivar a adoção de medidas básicas para a produção de cana, com base no desempenho prático e verificável (ORGANIZAÇÃO DE COOPERAÇÃO E DE DESENVOLVIMENTO ECONÓMICO, 2013). Nesse sentido, essas organizações estão promovendo produtos mais sustentáveis em escala global e, no longo prazo, investindo em suas necessidades de recursos futuros. Outro ponto positivo é o benefício da imagem institucional do setor sucroenergético, por possuir um diferencial ante os mercados importadores no que tange à sustentabilidade ambiental (OLIVEIRA et al., 2012).

A Bonsucro possui mais de 200 membros e parceiros do setor sucroenergético, o que equivale a uma área total de 954,62 hectares de cultivo de cana certificada, o equivalente a 3,5\% da produção global de cana (BONSUCRO, 2015). Diante desses fatos, a Bonsucro vem alcançando resultados positivos: primeiro, por ter sido bem sucedida em estabelecer o seu padrão de sustentabilidade e, segundo, pela crescente adesão de novos membros (MOURA; CHADDAD, 2012; ORGANIZAÇÃO DE COOPERAÇÃO E DE DESENVOLVIMENTO ECONÓMICO, 2013).

Se por um lado as certificações trazem os benefícios supracitados às organizações, por outro a sua adoção também pode impor barreiras competitivas para empresas menores, já que adaptar a organização sob todos os critérios exigidos gera custos que algumas empresas não são capazes de dispender (WALTER et al., 2011). Como consequência disso, os produtores que exportam biocombustíveis e que não têm condições de manter uma certificação, podem limitar suas áreas de atuação aos mercados que têm tal exigência (MOHR; BAUSCH, 2013).

Logo, entendendo que as certificações podem ser extremamente onerosas para as empresas (SHIKIDA, 2013), é preciso analisar se a adoção da certificação pode estar ligada ao porte da empresa, ou seja, no sentido de que quanto maior o seu porte, maior a probabilidade de ser esta uma empresa certificada - muito em função de uma maior disponibilidade de capital para arcar com os custos de certificação e sua manutenção. Contudo, no caso do setor sucroenergético, a capacidade produtiva das usinas é uma variável mais acurada do que a simples referência ao porte, para se medir capacidade de investimento. Assim, visando a testar essa relação nas empresas do setor sucroenergético é que a primeira hipótese foi levantada:

Hipótese 1: a capacidade produtiva está positivamente relacionada com a adoção de certificação sustentável.

\subsection{As Certificações e o IED no Setor Sucroenergético}

Na década de 90 , o setor sucroenergético brasileiro passou por um processo de estagnação em função da queda do preço do barril de petróleo e aumento do preço do açúcar. Tal fato levou a um arrefecimento dos investimentos no setor e à depreciação da indústria nacional, que foi instalada na década anterior (GARCIA; LIMA; VIEIRA, 2015). Entretanto, com a expansão do uso de carros com a tecnologia flex-fuel no início dos anos 2000 e a intensificação das preocupações concernentes ao uso de combustíveis não renováveis (CENTRO DE GESTÃO E ESTUDOS ESTRATÉGICOS, 2009), a indústria sucroalcooleira recebeu novo fôlego.

De acordo com Garcia, Lima e Vieira (2015) o potencial de expansão do setor, no Brasil, tem atraído investimentos estrangeiros, além do surgimento de novas rotas tecnológicas como o etanol de segunda e terceira gerações e a demanda em expansão. Simultânea à tendência de multinacionalização da indústria brasileira sucroenergética é esperada a injeção de capital externo para aumento de sua capacidade produtiva, bem como de seus mercados. A demanda por financiamento da atividade produtiva também é um dos direcionadores desse movimento no setor, visto que, em função da crise de 2008, diversas empresas brasileiras se tornaram insolventes. 
A internacionalização e o investimento no mercado de destino, para que as exportações ocorram, têm como principal objetivo o de intensificar as vendas (IGLESIAS; VEIGA, 2002). Como meio para que tal processo aconteça, a entrada em países estrangeiros pode acontecer por meio de exportações (este meio é bastante comum), estratégias de licenciamento, franchising, contratos de produção e a formação de joint-ventures (SOARES et al., 2011). Nesse sentido, uma forma de internacionalização fortemente identificada no setor são as aquisições e fusões de usinas por multinacionais ou grandes grupos financeiros estrangeiros.

Dessa forma, novas associações têm sido realizadas, tais como a Raízen Energia S/A: uma joint venture da companhia de petróleo holandesa Shell e a Cosan, maior produtora brasileira de cana-de-açúcar, as quais são certificadas pela BONSUCRO (MOHR; BAUSCH, 2013). Esse processo conduziu à consolidação de grupos com intensa participação do capital estrangeiro, haja vista que, em 2010, eles já representavam $20 \%$ do capital no setor (WILKINSON; HERRERA, 2010). A internacionalização dos mercados de biocombustíveis também impulsionou esse processo, dado o relacionamento comercial entre Estados Unidos, União Europeia e Brasil, os quais compartilham objetivos similares em relação à promoção de empregos verdes e descarbonização dos setores de transporte, entre outros (PACINI et al., 2013).

Oliveira et al. (2012) afirmam que esses grupos estrangeiros são capazes de fomentar o desenvolvimento do comércio internacional de etanol, por garantirem o fornecimento continuado e pela sua estrutura de exportação, que garantem a competitividade. Ainda, a intensa troca de tecnologias resultante da formação desses grupos tende "a aumentar as vendas externas, o valor agregado e a diversificação da pauta de exportações" (GARCIA; LIMA; VIEIRA, 2015, p. 166). Contudo, o acesso ao mercado internacional demanda o cumprimento de padrões e normas que visam a garantir a qualidade do produto e a garantia de que o processo produtivo não infrinja leis locais e internacionais.

Nos estudos sobre internacionalização, existe o predomínio de abordagens relacionadas às estratégias competitivas, contudo, permanece uma lacuna no que diz respeito às dimensões da sustentabilidade nesse processo (DIAS; SCHUSTER; DIAS, 2013). Exemplo da importância da sustentabilidade para exportações está nos critérios que têm sido propostos para promover biocombustíveis eficazmente sustentáveis; de modo a permitir a diferenciação entre produtos similares, principalmente dentre toda a cadeia produtiva, fruto das pressões advindas especialmente da Europa (ALVES; PINTO, 2013; WALTER et al., 2011).

O estudo conduzido por Bokpin (2017) analisou dados de 1990 a 2013, em toda a África, a fim de investigar o impacto das entradas de capital estrangeiro no ecossistema dentro da agenda da sustentabilidade. Ele mostrou que, embora exista a possibilidade do crescimento econômico, o que no setor sucroenergético poderia aumentar a capacidade de moagem das usinas, os seus resultados revelaram um aumento na degradação ambiental, ou seja, não há evidência de que o IED está relacionado com a busca pela sustentabilidade, e consequentemente com a adoção de certificações da área. Além disso, estudos revelaram que o impacto do IED depende da capacidade de absorção que pode variar desde o país de recebimento do investimento, quanto do setor investido, além da capacidade de aprendizagem que as organizações possuem para que haja o benefício do capital estrangeiro (ANWAR; NGUYEN, 2014; BRUHN et al., 2017; DESBORDES; WEI, 2017).

Outros autores alegam que as atividades de fusão e aquisição envolvendo o capital estrangeiro apresentam efeitos principalmente indiretos, pois a melhoria da capacidade só ocorrerá se a organização for capaz de internalizar as externalidades advindas do investimento estrangeiro, e assim haveria melhorias de seu desempenho e a busca por melhoria nos seus processos (BRUHN et al., 2017; NARULA, 2014; NARULA; DUNNING, 2010).

Alguns estudos apontam que a adoção de determinadas certificações garante às empresas não somente a certeza de cumprir as demandas legais, locais e internacionais, mas também a possibilidade de formalizar uma imagem positiva frente aos seus stakeholders, o que pode levar a vantagens competitivas (CHRISTIANSEN; KARDEL, 2005) e oportunidades de economia de recursos (SILVA; RIBEIRO, 2005).

Para as empresas brasileiras do setor, cabe a ressalva feita por Alves e Pinto (2013) de que as certificações socioambientais têm sido adotadas com o objetivo de minimizar os efeitos no mercado externo gerados pelo questionamento das práticas sociais e ambientais na produção da cana-de-açúcar.

Nesse sentido, é possível assumir que o investimento estrangeiro no setor induz à adoção de certificações que respondam às pressões legais, sociais e ambientais (nesse caso, a Bonsucro) em função da necessidade de adequação às regulamentações dos países sede dos grupos no exterior, assim como dos mercados consumidores estrangeiros. Além 
disso, o investimento estrangeiro pode promover maior acesso a capital que financie a adoção da certificação e a sua manutenção, já que, conforme Vicente (2012), atualmente o acesso a certificações socioambientais é economicamente viável apenas para empresas de maior porte já que estas têm um maior potencial de obtenção de receita.

Como consequência disso, é possível levantar a hipótese de que empresas controladas por grupos estrangeiros possuem maiores chances de aderir às certificações de sustentabilidade. Para testar essa relação é que foi formulada a segunda hipótese da pesquisa, a saber: Hipótese 2: o controle de capital estrangeiro está positivamente relacionado com a adoção de certificação sustentável.

A próxima seção apresenta a metodologia que foi utilizada para a consecução desta pesquisa.

\section{METODOLOGIA}

\subsection{Amostra e Coleta de Dados}

A abordagem empírica desta pesquisa é centrada nas empresas no setor sucroenergético, mais especificamente nas usinas de cana-de-açúcar do estado de São Paulo. Segundo a União da Indústria de Canade-açúcar (UNIÃO DA INDÚSTRIA DE CANA-DEAÇÚCAR, 2013), o estado de São Paulo respondeu na safra 2013/2014 por mais da metade da moagem de cana de açúcar no Brasil.

A partir de uma lista inicial de empresas obtida junto à UNICA, foi iniciada a coleta de dados secundários das variáveis da pesquisa: certificação, capital estrangeiro e capacidade produtiva. A coleta de dados foi realizada em quatro passos:

Identificação das usinas sucroenergéticas situadas dentro do estado de São Paulo associadas à UNICA.

Investigação em sites corporativos, jornais e portais setoriais para identificar quais das usinas selecionadas no passo 1 foram adquiridas por capital estrangeiro.

Levantamento nos sites corporativos das empresas selecionadas no passo 1 se elas possuíam a certificação Bonsucro, e a fim de confirmar os resultados encontrados, a página oficial da Bonsucro também foi consultada.

Por fim, a capacidade de moagem por safra foi averiguada em sites corporativos e portais setoriais.

Quando as informações não foram encontradas ou houve divergências entre as fontes pesquisadas, os dados foram obtidos mediante contato direto com as empresas por e-mail e telefone. A amostra foi determinada por conveniência, de forma não aleatória, em função da disponibilidade de informações e da cooperação das empresas em fornecer dados faltantes, partindo da lista das empresas associadas a UNICA. Tal procedimento, seguido das etapas acima mencionadas, tornou possível a seleção de uma amostra composta por 100 usinas, que representam $58 \%$ das empresas em operação no estado de São Paulo. A população total das usinas sucroalcooleiras do estado de São Paulo compreende 172 unidades produtivas (CRESCE..., 2013).

\subsection{Modelo Econométrico e Variáveis}

Os dados foram analisados com o modelo multivariado de regressão logística binomial (MENARD, 2002; PINDYCK; RUBINFELD, 1998), para avaliar a influência do capital estrangeiro e da capacidade produtiva das empresas, nas probabilidades ( 0 a 1) de certificação das empresas do setor sucroenergético. Essa técnica foi escolhida porque a variável dependente é dicotômica (o que não permite usar um modelo de probabilidade linear), e porque ela é mais robusta em relação aos pressupostos que outras técnicas, como a análise discriminante (GREENE, 2011). A $i$-nésima decisão de uma empresa adotar a certificação é representada pela Equação 1, que segue abaixo:

$C E R T_{i}^{*}=\boldsymbol{I E} \boldsymbol{D}_{i} \boldsymbol{A}+\boldsymbol{C A} \boldsymbol{P}_{i} \boldsymbol{B}+\varepsilon_{i}$

Em que $\boldsymbol{I E} \boldsymbol{D}_{i}$ identifica investimento estrangeiro direto (HYMER, 1960), avaliado de forma binária, dado pelo controle acionário por capital externo ou não, e $\boldsymbol{A}$ contém os coeficientes estimados de $\boldsymbol{I} \boldsymbol{E} \boldsymbol{D}_{i}$. Essa opção metodológica atende ao objetivo da pesquisa por diferenciar investimentos de portfólio, puramente financeiro, do investimento estrangeiro direto. Isso porque a premissa dos efeitos da matriz na subsidiária não tem suporte no primeiro tipo de investimento, que é de baixo envolvimento (RUGMAN; VERBEKE; NGUYEN, 2011). $\boldsymbol{C A P}_{i}$ é a capacidade de moagem em milhões de toneladas por ano e $\boldsymbol{B}$ é o seu coeficiente. Para as usinas que apresentavam a capacidade de moagem em toneladas por dia, foi realizado o cálculo com base em 180 dias de safra, pois segundo a estimativa da safra realizada pela UNICA (UNIÃO DA INDÚSTRIA DE CANA-DE-AÇÚCAR, 2013), a moagem se inicia em abril, e tem uma queda brusca entre setembro e outubro, totalizando 6 meses, que é aproximadamente 180 dias. representa a adoção de certificação sustentável, ou seja, se as empresas são certificadas ou não pela Bonsucro. Embora existam outras certificações relacionadas ao conceito de sustentabilidade, como a Rainforest Alliance Certified, a Ethical Biotrade e a EcoSocial, foi escolhida a Bonsucro, 
pelo fato de que esta (1) dimensiona a sustentabilidade em coerência com o Triple Bottom Line e (2) foi delineada de acordo com as especificidades do setor sucroenergético. A variável foi operacionalizada da seguinte forma:

$C E R T_{i}=1$ (adota certificação Bonsucro)

$C E R T_{i}=0$ (não adota certificação Bonsucro)

O modelo logit foi estimado usando o procedimento de máxima verossimilhança que resulta em estimativas de parâmetros que são consistentes e assintoticamente eficientes para o tamanho da amostra (GREENE, 2011). A escolha por usar uma variável de controle relacionada a porte, a "capacidade de moagem", foi baseada em artigos que apontam tal variável como uma possível determinante das decisões estratégicas empresariais, no que tange à adoção de certificações no setor sucroalcooleiro (SHIKIDA, 2013; VICENTE, 2012; WALTER et al., 2011).

Ainda, optou-se pela variável IED não apenas por seu impacto direto no crescimento e expansão das atividades organizacionais no país de destino, mas também por seus efeitos indiretos e outros objetivos ligados a ele.

\section{RESULTADOS}

As empresas que compõem a amostra possuem capacidade de moagem média de 2,69 milhões de toneladas por ano, com mínimo de 0,66 e máximo de 8,50. Dentre elas, 22\% possuem a certificação Bonsucro. Quanto ao investimento estrangeiro direto, ele representa o controle acionário de $24 \%$ das empresas. Na Tabela 1, é possível verificar a distribuição entre os países de origem do IED. A concentração de mais da metade na França deve-se à forte atuação dos grupos Louis Dreyfus Commodities e Tereos Internacional.
TABELA 1 - Distribuição do IED nas usinas por país de origem

\begin{tabular}{cc}
\hline País de origem (IED) & Participação na amostra (\%) \\
\hline França & $54 \%$ \\
EUA & $17 \%$ \\
China & $17 \%$ \\
Índia & $8 \%$ \\
Suíça & $4 \%$ \\
\hline
\end{tabular}

Fonte: Elaborado pelos autores

A Tabela 2 apresenta os resultados da análise da influência do capital estrangeiro e da capacidade produtiva na adoção de certificações sustentáveis, conforme detalhado na metodologia. A estatística da função de verossimilhança (-2LL) testa se o modelo estimado como um todo é significante; o resultado $(\mathrm{p}<0,05)$ suporta a análise de cada variável no modelo. Ademais, os testes de Pearson e Hosmer-Lemeshow não são significativos ( $\mathrm{p}>0,05)$, indicando a boa qualidade de ajuste do modelo, já que não há diferenças significativas entre as frequências previstas e observadas. Corroborando esses indicadores, a área da curva Receiver Operating Characteristic (ROC) acima de 0,70 sugere uma qualidade preditiva satisfatória. Por fim, foi avaliada a multicolinearidade do modelo por meio das medidas de Variance Inflation Factor (VIF) e tolerância. Os valores encontrados foram, respectivamente, 1,06 e 0,95 , não indicando problemas de multicolinearidade, já que variáveis completamente ortogonais umas às outras possuem valor 1 de VIF e tolerância.

Para a Hipótese 1: a capacidade produtiva está positivamente relacionada com a adoção de certificação sustentável, o modelo logístico apresenta forte suporte estatístico $(\mathrm{p}<0,05)$. Calculadas as razões de chance, o

TABELA 2 - Estimativas dos parâmetros do modelo logit para a adoção de certificação

\begin{tabular}{|c|c|c|c|c|}
\hline \multirow[b]{2}{*}{ Variáveis } & \multirow[b]{2}{*}{$\beta$ (erro padrão) } & \multicolumn{3}{|c|}{ Intervalo de confiança $(95 \%)$} \\
\hline & & Limite inferior & Razões de chance & Limite superior \\
\hline Constante & $-2.26 * * *(0,52)$ & & & \\
\hline Capital estrangeiro & $-0,08(0,58)$ & 0,29 & 0,92 & 2,91 \\
\hline Capacidade produtiva & $0,35 * *(0,15)$ & 1,05 & 1,42 & 1,91 \\
\hline $\begin{array}{l}-2 \operatorname{LL} \chi^{2}(2)=5,57 ; p<0,05 \\
\text { Pearson } \chi^{2}(74)=76,60 ; p>0 \\
\text { Hosmer-Lemeshow } \chi 2(8)=7 \\
\text { Área da curva ROC }=0,7075\end{array}$ & $\mathrm{p}>0,05$ & & & \\
\hline Nota: $* * * \mathrm{p}<0,01 ; * * \mathrm{p}<0,05$ & $0,1$. Modelo $\chi^{2}$ & $57, p<0,05$ & & \\
\hline
\end{tabular}


aumento de cada milhão de toneladas na capacidade de moagem representa um incremento médio de $42 \%$ nas chances de adoção de certificações sustentáveis. Na Figura 1, é possível ver o aumento nas chances de uma usina possuir certificação Bonsucro. Enquanto uma dada usina com capacidade de moagem de 4 milhões de toneladas/ano tem $29 \%$ de chances de possuir certificação Bonsucro $(\mathrm{p}<0,01)$, uma outra com o dobro da capacidade tem $70 \%$ ( $p<0,01)$.

Outra questão que o gráfico indica é que, a despeito de os intervalos de confiança aumentarem progressivamente, a probabilidade de adoção da certificação e a capacidade produtiva parecem guardar entre si uma relação linear, ou seja, em princípio, o gráfico sugere que não há um ponto de inversão, no qual a capacidade cresça a ponto de diminuir as chances de adoção, comportamento que seria caracterizado visualmente por uma curva em "U invertido".

Com relação à Hipótese 2: o investimento externo direto está positivamente relacionado com a adoção de certificação sustentável, não foram encontradas evidências empíricas que a suportem $(p>0,10)$. Esse resultado mostra que a origem do capital controlador (nacional ou estrangeira) não diferencia a decisão das empresas em investir na certificação da Bonsucro, ouu seja, a mudança de controle não representa uma mudança nas probabilidades de adoção de práticas sustentáveis.

\section{DISCUSSÃO}

Sobre a Hipótese 1: a capacidade produtiva está positivamente relacionada com a adoção de certificação sustentável, que foi estatisticamente confirmada, é importante destacar que dentro da lógica teórica, não há impedimentos para que uma empresa de menor capacidade produtiva adote práticas sustentáveis. Contudo, identificou-se que a adoção de certificações no setor é pautada pela capacidade de moagem das empresas: quanto maior a capacidade da empresa, maior a probabilidade de adoção. Potencialmente, também se pode depreender que as usinas maiores vendem para mercados mais especializados - e que, portanto, são mais exigentes, tendo como pré-requisito a certificação. Mas esse resultado suscita algumas considerações a respeito dessa questão nas empresas de menor capacidade produtiva.

A primeira é que a sustentabilidade é reconhecida como uma questão estratégica, principalmente para as grandes empresas. Dessa forma, mais importante que as barreiras práticas, são as barreiras cognitivas para colocar essas empresas dentro do paradigma sustentável. Elas, em geral, possuem um processo decisório mais simplificado, devido às suas operações mais ágeis e ao fato de se concentrarem em domínios de mercado mais restritivos (OBSTFELD, 2012).

A segunda é que as empresas menores possuem maiores restrições de recursos (OBSTFELD, 2012). Assim, as empresas menores enfrentam maiores dificuldades em aderirem às práticas sustentáveis sem retorno financeiro imediato ou que requerem mudanças sistemáticas. Analisando o problema de uma perspectiva de redes (ALCADIPANI; TURETA, 2009), devido à falta de

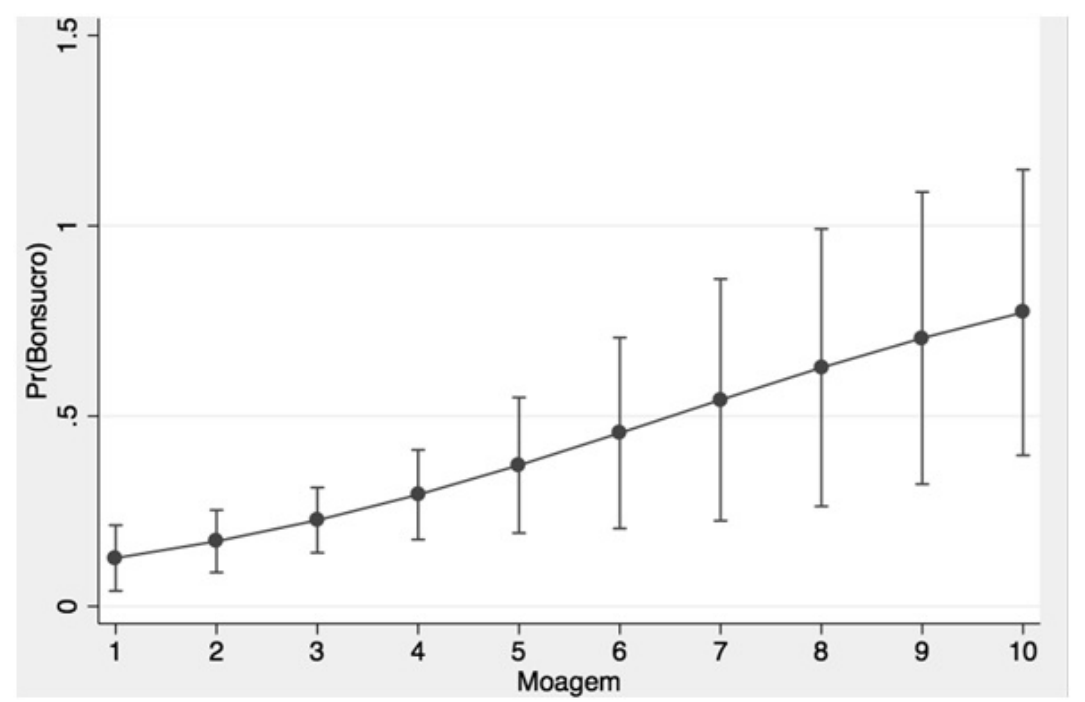

FIGURA 1 - Distribuição das probabilidades de adoção da certificação Bonsucro em relação à capacidade de moagem Nota: Capacidade de moagem em milhões de toneladas por ano

Organizações Rurais \& Agroindustriais, Lavras, v. 19, n. 2, p. 137-148, 2017 
poder, as empresas menores vão depender mais do comportamento sustentável dos outros integrantes da rede do que as empresas maiores. Contudo, se as empresas forem capazes de integrar a sustentabilidade dentro da estratégia competitiva e promover situações do tipo ganhaganha, ganharão visibilidade para superar, ao menos em parte, o que lhes falta em tamanho.

Diante disso, não é cabível uma estratégia baseada em reformular ou adaptar proposições normativas sustentáveis para um grupo específico de empresas, que, em princípio, não está à altura do desafio nos moldes atuais. É preciso o fomento de uma cultura de compartilhamento de responsabilidade que possa complementar as iniciativas individuais das pequenas empresas no ecossistema. A busca ativa e mútua das empresas por parceiros que adotem práticas sustentáveis pode ajudar nesse sentido.

Quanto à ausência de suporte estatístico para confirmar a Hipótese 2: o investimento externo direto está positivamente relacionado com a adoção de certificação sustentável, esse resultado pode ser visto como algo ruim, na medida em que contraria as expectativas de que os investimentos estrangeiros sejam capazes de trazer não apenas capital, mas melhorar o ambiente competitivo nacional (CASTRO; FERNANDES; CAMPOS, 2013).

A negação da Hipótese 2 pode ser sustentada pela constatação de Bokpin (2017), já que para ele o impacto positivo dos investimentos diretos estrangeiros na sustentabilidade ambiental só ocorrerá se houver fortes instituições governamentais e de qualidade que possam fiscalizar a conduta das empresas financiadas pelos fluxos de IED, além da capacidade de aprendizagem e absorção que as organizações precisariam apresentar diante do investimento estrangeiro. Além da capacidade de aprendizagem e absorção, o impacto do IED também depende de outros aspectos relativos ao setor e país de recebimento (ANWAR; NNGUYEN, 2014; BRUHN et al., 2017; DESBORDES; WEI, 2017). A negação dessa hipótese pode dizer respeito ao fato das organizações obterem melhorias a partir do capital estrangeiro, apenas sob a condição de absorção das externalidades oriundas desses investimentos nos seus processos organizacionais (BRUHN et al.; 2017; NARULA, 2014; NARULA; DUNNING, 2010).

Igualmente, os resultados corroboram também com as conclusões de Dias, Schuster e Dias (2013) ao estudarem o setor químico: um alto nível de internacionalização não reflete na busca por práticas sustentáveis. Isso não diminui a importância do investimento estrangeiro nas empresas do setor sucroenergético para a manutenção da produção no longo prazo e investimento de expansão. Apenas evidencia a não existência de uma relação estatisticamente significante entre o capital estrangeiro e a adoção da certificação.

Ademais, é interessante ressaltar que na distribuição das origens do investimento externo, $75 \%$ têm origem em países desenvolvidos, onde a questão da sustentabilidade já é uma temática mais amadurecida.

Desse modo, os resultados também sugerem que a necessidade de adequação às regulamentações dos países sede dos grupos não se estende à atuação desses mesmos grupos no exterior. Isso reforça a importância da articulação de medidas locais que promovam a sustentabilidade nos países que recebem os investimentos a fim de evitar que o "esverdeamento" das operações nos países sede signifique apenas a descentralização das atividades de risco socioambiental para os países em desenvolvimento.

\section{CONSIDERAÇÕES FINAIS}

Esta pesquisa teve como objetivos analisar a influência do investimento estrangeiro direto e da capacidade produtiva na adoção de certificações sustentáveis no setor sucroenergético brasileiro. A hipótese de que a capacidade produtiva esteja positivamente relacionada com a adoção de certificação sustentável foi estatisticamente significante. Porém, a segunda hipótese, de que o investimento estrangeiro direto atue como indutor à adoção dessas práticas, não foi aceita.

Os resultados sugerem que o IED em países emergentes pode resultar mais em degradação ambiental do que em busca por certificações sustentáveis como trazido por Bokpin (2017). Narula (2014) ainda alega que o IED nos países menos desenvolvidos, geralmente, ocorre por busca de recursos naturais, e isso pode implicar em uma atividade de baixo valor agregado, além da baixa intenção de despesa de capital em instalações e equipamentos, ou seja, o fluxo estrangeiro não influencia a busca por melhorias do desempenho e nem por certificações sustentáveis.

Por outro lado, adaptar as organizações sob todos os critérios exigidos para a obtenção dessas certificações pode gerar custos e investimentos que nem todas as empresas são capazes de dispender. As empresas de menor porte podem buscar melhorar seus processos visando aatender os requisitos das certificações de maneira mais paulatina, a fim de se diferenciarem no mercado e buscarem a sustentabilidade. Elas podem analisar o quanto o investimento traria de retorno para elas, utilizando da gestão estratégica para tomar decisões. 
A sociedade civil também pode auxiliar na busca por alternativas mais sustentáveis cobrando que as instituições governamentais e de qualidade possam fiscalizar a conduta das organizações, tanto as que são financiadas por IED (BOKPIN, 2017), quanto as de capital nacional.

A busca por resultados sustentáveis tem crescido cada vez mais, principalmente com o lançamento dos Objetivos do Desenvolvimento Sustentável pela Organização das Nações Unidas em 2015, que convidam a todos buscar soluções aos desafios do planeta em vista da sustentabilidade (BRASIL, 2015). Logo, é importante que as organizações insiram a sustentabilidade como uma estratégia de posicionamento visando à vantagem competitiva, o valor e o retorno que ela é capaz de gerar.

A principal limitação desta pesquisa é relativa à abordagem cross section (transversal). Como as empresas foram analisadas em um momento específico do tempo, os resultados desse estudo devem ser ponderados por essa limitação: não foram analisadas as mesmas empresas ao longo do tempo para que se verificassem mudanças no seu comportamento em relação à adoção de práticas sustentáveis decorrentes da troca do controle por meio de investimento estrangeiro direto.

Como sugestão de estudos futuros, seria de grande contribuição para a temática de sustentabilidade explorar as motivações e os processos pelos quais empresas menores integram práticas sustentáveis em seus modelos de negócio. Além disso, são oportunidades de pesquisa estudos complementares que investiguem outras variáveis que possam explicar a decisão das organizações por certificações, tais como estratégias competitivas, adequação às normas locais e internacionais e posicionamento de mercado em prol da sustentabilidade.

\section{REFERÊNCIAS}

ALCADIPANI, R.; TURETA, C. Teoria ator-rede e estudos críticos em administração: possibilidades de um diálogo. Cadernos EBAPE, Rio de Janeiro, v. 7, n. 3, p. 406-418, set. 2009.

ALVES, L. R.; PINTO, S. S. Ações sustentáveis e a busca pela certificação do etanol no setor sucroenergético. Revista Cognitio, São Paulo, v. 1, n. 1, p. 1-19, 2013.

ANWAR, S.; NGUYEN, L. P. Is foreign direct investment productive? A case study of the regions of Vietnam. Journal of Business Research, Athens, v. 67, n. 7, p. 1376-1387, July 2014.
BOLIS, I.; BRUNORO, C. M.; SZNELWAR, L. I. Mapping the relationships between work and sustainability and the opportunities for ergonomic action. Applied Ergonomics, Guildford, v. 45, n. 4, p. 1225-1239, July 2014.

BONSUCRO. 2015. Padrão de Produção Bonsucro. Disponível em <http://bonsucro.com/site/productionstandard/>. Acesso em: 01 set. 2017.

BOPKIN, G. A. Foreign direct investment and environmental sustainability in Africa: the role of institutions and governance. Research in International Business and Finance, Amsterdam, v. 39, p. 239-247, Jan. 2017.

BRASIL. Governo Federal. Transformando nosso mundo: a agenda 2030 para o desenvolvimento sustentável. São Paulo: ONUBR, 2015. 42 p.

BRITISH STANDARDS INSTITUTION - BSI. Em números. London: BSI, 2015. Disponível em: $<$ http://Bonsucro.com/site/ in-numbers/?lang=pt $>$. Acesso em: 25 mar. 2015.

. Production standard: guia de auditoria para produção padrão. London: BSI, 2013. Disponível em: $<$ http://Bonsucro.com/site/production-standard/>. Acesso em: 18 set. 2013.

BRUHN, N. C. P. et al. Mergers and acquisitions in Brazilian industry: a study of spillover effects. International Journal of Productivity and Performance Management, Oxford, v. 66, n. 1, p. 51-77, 2017.

CASTRO, P. G.; FERNANDES, E. A.; CAMPOS, A. C. The determinants of foreign direct investment in Brazil and Mexico: an empirical analysis. Procedia Economics and Finance, Netherlands, v. 5, p. 231-240, 2013.

CENTRO DE GESTÃO E ESTUDOS ESTRATÉGICOS - CGEE. Bioetanol combustível: uma oportunidade para o Brasil. Brasília: CGEE, 2009. 536 p.

CERTIFICAÇÃO Bonsucro. SGS, Barueri, 2013. Disponível em: <http://www. sgsgroup.com.br/pt-BR/ Sustainability/Environment/Energy-Services/AlternativeFuels/Bonsucro-Certification.aspx>. Acesso em: 9 set. 2013.

CHRISTIANSEN, K.; KARDEL, D. Environmental certificates - danish lessons. Journal of Cleaner Production, Amsterdam, v. 13, n. 8, p. 863-866, June 2005.

Organizações Rurais \& Agroindustriais, Lavras, v. 19, n. 2, p. 137-148, 2017 
CRESCE o número de usinas certificadas pelo Bonsucro. Nova Cana, Curitiba, 2013. Disponível em: <http:// www.novacana.com/n/cana/meio-ambiente/cresce-usinascertificadas-Bonsucro-040313/\#>. Acesso em: 18 set. 2013.

DESBORDES, R.; WEI, S. J. The effects of financial development on foreign direct investment. Journal of Development Economics, Amsterdam, v. 127, p. 153-168, July 2017.

DIAS, V. V.; SCHUSTER, M. S.; DIAS, R. R. Orientação da gestão sustentável de uma empresa química com atividade internacional. Revista Eletrônica de Negócios Internacionais, São Paulo, v. 8, n. 1, p. 68-87, 2013.

GARCIA, J. R.; LIMA, D. A. L. L.; VIEIRA, A. C. P. A nova configuração da estrutura produtiva do setor sucroenergético brasileiro: panorama e perspectivas. Revista de Economia Contemporânea, Rio de Janeiro, v. 19, n. 1, p. 162-184, jan./abr. 2015.

GREENE, W. Econometric analysis. 7. ed. Upper Saddle River: Prentice Hall, 2011. 1232 p.

GUIDO, A. L. B.; LIMA, R. T. Empresas transnacionais e internacionalização: uma análise bibliométrica dos termos. Revista Brasileira de Administração Científica, Aquidabã, v. 3, n. 3, p. 83-96, jul./dez. 2012.

HATANAKA, M. Governing sustainability: examining audits and compliance in a third-party-certified organic shrimp farming project in rural Indonesia. Local Environment, Abingdon, v. 15, n. 3, p. 233-244, 2010.

IGLESIAS, R. M.; VEIGA, P. M. Promoção das exportações via internacionalização das firmas de capital brasileiro. In: PINHEIRO, A. C.; MARKWALD, R.; PEREIRA, L. V. O desafio das exportações. Rio de Janeiro: BNDES, 2002. 2002. p. 369-446.

KLINE, J. M. Evaluate sustainable FDI to promote sustainable development. Columbia FDI Perspectives, New York, n. 82, p. 1-3, Nov. 2012.

MENARD, S. Applied logistic regression analysis. 2. ed. Thousand Oaks: Sage, 2002. 128 p.

MOHR, A.; BAUSCH, L. Social sustainability in certification schemes for biofuel production: an explorative analysis against the background of land use constraints in Brazil. Energy, Sustainability and Society, London, v. 3, n. 6, p. 1-14, Dec. 2013.

MORAES, M. A. F. D.; OLIVEIRA, F. C. R.; DIASCHAVEZ, R. A. Socio-economic impacts of Brazilian sugarcane industry. Environmental Development, Amsterdam, v. 16, p. 31-43, Dec. 2015.

MOURA, P. T.; CHADDAD, F. R. Collective action and the governance of multistakeholder initiatives: a case study of Bonsucro. Journal on Chain and Network Science, Wageningen, v. 12, n. 1, p. 13-24, 2012.

NARULA, R. Foreign direct investment as a driver of industrial development: why is there so little evidence? In: TULDER, R. V.; VERBEKE, A.; STRANGE, R. (Ed.). International business and sustainable development. Bingley: Emerald Group Publishing, 2014. p. 45-67.

NARULA, R.; DUNNING, J. H. Multinational enterprises, development and globalisation: some clarifications and a research agenda. Oxford Development Studies, Oxfordshire, v. 38, n. 3, p. 263-287, Sept. 2010.

OBSTFELD, D. Creative projects: a less routine approach toward getting new things done. Organization Science, Providence, v. 23, n. 6, p. 1571-1592, Feb. 2012.

OLIVEIRA, E.; PEREIRA, R. S.; GASPAR, M. A. Análise da produção científica nacional sobre gestão ambiental no setor sucroenergético brasileiro. Revista Gestão \& Sustentabilidade Ambiental, Florianópolis, v. 3, n. 1, p. 39-63, abr./set. 2014.

OLIVEIRA, S. M. et al. Certificação da indústria do etanol brasileiro no contexto dos stakeholders. Revista em Agronegócio e Meio Ambiente, Maringá, v. 5, n. 2, p. 283-309, maio/ago. 2012.

ORGANIZAÇÃO DE COOPERAÇÃO E DE DESENVOLVIMENTO ECONÓMICO - OCDE. Development Co-operation Report 2012: lessons in linking sustainability and development. London: OCDE, 2013. 296 p.

PACINI, H. et al. The price for biofuels sustainability. Energy Policy, Surrey, v. 59, p. 898-903, Aug. 2013. 
PINDYCK, R. S.; RUBINFELD, D. L. Econometric models and economic forecasts. Boston: Irwin, 1998. $634 \mathrm{p}$.

RUGMAN, A. M.; VERBEKE, A.; NGUYEN, Q. T. K. Fifty years of international business theory and beyond. Management International Review, Wiesbaden, v. 51, n. 6, p. 755-786, Dec. 2011.

RUVIARO, C. F. et al. Life cycle assessment in Brazilian agriculture facing worldwide trends. Journal of Cleaner Production, Amsterdam, v. 28, p. 9-24, June 2012.

SAMPAIO, C. M. S.; BORSCHIVER, S.; MORGADO, C. R. V.A contribuição de sistemas de gestão à sustentabilidade da produção de etanol no Brasil. Revista Univap, São José dos Campos, v. 18, n. 31, p. 87-101, jun. 2012.

SHIKIDA, P. F. A. Expansão canavieira no CentroOeste: limites e potencialidades. Revista de Política Agrícola, Brasília, v. 22, n. 2, p. 122-137, abr. 2013.

SILVA, D.A.; RIBEIRO, H. Certificação ambiental empresarial e sustentabilidade: desafios da comunicação. Saúde e Sociedade, São Paulo, v. 14, n. 1, p. 52-67, jan./abr. 2005.

SMERENICK, K. R.; ANDERSEN, P. A. The diffusion of environmental sustainability innovations in North American hotels and ski resorts. Journal of Sustainable Tourism, Clevedon, v. 19, n. 2, p. 171-196, Oct. 2011.

SOARES, M. C. et al. Estrutura organizacional e internacionalização de empresas: um estudo de caso no setor sucroenergético do Brasil. Revista Ibero-Americana de Estratégia, São Paulo, v. 10, n. 3, p. 49-65, dez. 2011.

UNIÃO DA INDÚSTRIA DE CANA-DE-AÇÚCAR UNICA. Setor Sucroenergético FAQ. Única, São Paulo, 2015. Disponível em: $<$ http://www.unicadata.com.br/faq $>$. Acesso em: 29 nov. 2015.

. Unicadata. Única, São Paulo, 2013. Disponível em: <http://www.unicadata.com.br>. Acesso em: 28 set. 2013.

UNITED NATIONS. General Assembly. Disponível em: $<$ http://www.un.org/documents/ga/res/42/ares42-187. htm>. Acesso em: 19 set. 2017.

USINAS de açúcar e álcool no estado: São Paulo. Nova Cana, Curitiba, 2017. Disponível em: <https://www. novacana.com/usinas-brasil/sudeste/sao-paulo/page4/>. Acesso em: 17 de jul. 2017.

WALTER, A. et al. Sustainability assessment of bioethanol production in Brazil considering land use change, GHG emissions and socio-economic aspects. Energy Policy, Surrey, v. 39, n. 10, p. 5703-5716, Oct. 2011.

WANG, D. T. et al. When does FDI matter? The roles of local institutions and ethnic origins of FDI. International Business Review, Amsterdam, v. 22, n. 2, p. 450-465, Apr. 2013.

WILKINSON, J.; HERRERA, S. Biofuels in Brazil: debates and impacts. The Journal of Peasant Studies, Amsterdam, v. 37, n. 4, p. 749-768, Sept. 2010. 